Agric. Biol. Chem., 42 (4), $717 \sim 722,1978$

\title{
Postnatal Changes in Activities of Acetylcholinesterase and Cholinesterase in the Brain of a Methylazoxymethanol-induced Microencephalic Rat
}

\author{
Yukio Nagata, Yukio Nakamura and Tadashi Watanabe \\ Department of Agricultural Chemistry, Faculty of Agriculture, \\ Gifu University, Naka, Kagamigahara 504, Japan
}

Received August 24, 1977

\begin{abstract}
Activities of $\mathrm{AChE}$ and $\mathrm{ChE}$ per $\mathrm{g}$ wet weight of the cerebrum were higher in the cerebrum of the MAM-induced microencephalic rats that were the offspring of the mother rats injected on the 15 th day of pregnancy with MAM-acetate than in the normal rats cerebrum. They increased for 30 days after birth and were maintained constant thereafter. The activity of $\mathrm{AChE}$ more increased in the cerebral subcortex than in other regions. With the increase in dose of the drug administered to mother rats, the cerebral weight of their offspring decreased gradually whereas $\mathrm{AChE}$ activity per $\mathrm{g}$ wet weight of their cerebrum increased. These findings support existence of plasticity in the cerebrum.
\end{abstract}

Cycad plants (Cycas circinalis and $C$. revolta) were utilized as food and feed in the Okinawa and Guam Islands. ${ }^{1 \sim 3}$, Their leaves, stems and nuts contain a toxic compound, cycasin, which was identified with methylazoxymethyl- $\beta$-D-glucoside. ${ }^{4)} \quad$ Although carcinogenic and neurotoxic activity of the toxin was not noticed at that time, the compound was noted as the substance causing amyotrophic lateral sclerosis in men and cows eating the leaves or nuts of cycad. ${ }^{5}$ Laqueur et al. found the nuts hepatotoxic and carcinogenic. The toxic activity was not caused by cycasin itself but by its aglycone, i.e., MAM.? When pregnant rats were injected with MAM in the begining of the third trimester of pregnancy, their offspring became microencephalic. ${ }^{8}$ The weight of the cerebral hemisphere of them was significantly lower than that of normal animals. Nagata et al. showed MAM injected into pregnant rats was transferred via placenta to the brain of foetal rats where it methylated the 7-position of guanine of DNA. ${ }^{9}$ Injected MAM markedly inhibited growth of the cerebrum of the offspring and the amounts of DNA and RNA in the reduced organ were half

Abbreviations used: MAM, methylazoxymethanol; AChE, acetylcholinesterase (EC 3.1.1.7); ChE, cholinesterase (EC 3.1.1.8); AcTCh, acetylthiocholine; BuTCh, S-butyrylthiocholine; ACh, acetylcholine. as much as those of the nucleic acids in the normal one. The nucleic acids contents were not restored to the normal level in all their lives. ${ }^{10,11)}$

On the other hand, learning ability of the microencephalic rat was inferior to that of the normal animal. However, the extent of inferiority was not so large as the degree of the reduction in telencephalic mass. ${ }^{11 \sim 13}$ ) Rosenzweig reported that $\mathrm{AChE}$ activity was increased by high synaptic transmission including experience and training. ${ }^{14)}$ His finding suggested the next working hypothesis: AChE activity in the reduced cerebrum of MAMinduced microencephalic rats should increase in order that the microencephalic rats live adapting themselves to surrounding circumsstances. The present study was performed to verify this hypothesis. Since $\mathrm{ChE}$ is primarily localized in glial cells in neuron tissues, ${ }^{15}$ it was also examined in this study by determining ChE activity whether metabolism of glial cells was influenced by the prenatal treatment with MAM.

\section{MATERIALS AND METHODS}

Animals. Rats of a Wistar strain were fed a commercial stock diet ad libitum in free access to tap water. Three or 4 female rats were housed with a male in a cage. The day of mating was determined by ex- 
amination of vaginal lavages for the presence of sperm. All pregnant rats were caged singly. They were injected intraperitoneally with $24 \mathrm{mg}$ of MAM-acetate (Mann Research Laboratory, New York, N.Y.) in $0.9 \% \mathrm{NaCl}$ per $\mathrm{kg}$ of body weight on the 15 th day of pregnancy unless otherwise mentioned. The offspring from the mothers injected with MAM-acetate were called MAM-induced microencephalic rats or simply microencephalic rats in this paper. They were weaned on day 25 after birth. The males were housed in a group of 2 or 3 in a cage after day 40 when the females were removed. The male animals were used in this study on day 30,60 , and 90 , whereas both females and males were used on day 10 and 20 .

Preparation of crude enzyme solution. All animals were weighed and killed by decapitation at 10 a.m. The brains were rapidly transferred into a chilled $0.3 \mathrm{M}$ sucrose solution. The cerebra were obtained by an incision through the olfactory lobes and the cerebral peduncles, and weighed immediately after removal of blood and other adherings. They were homogenized at $0^{\circ} \mathrm{C}$ for $5 \mathrm{~min}$ in appropriate volumes of the chilled $0.1 \mathrm{M}$ phosphate buffer $(\mathrm{pH} 8.0)$.

Preparation of the subcortex. The cerebral subcortex (cerebrum with the grey-matter stripped off) was obtained by gross dissection with a scalpel from the freshly decapitated brain on an ice-cooled glass plate. The cerebral subcortex of a rat could be removed from the cerebrum with almost no grey-matter adhering. The subcortical tissue included, of course, all the white-matter of the cerebrum. About 450 to $590 \mathrm{mg}$ of the subcortical tissue was obtained from the cerebrum of a control rat and approximate 220 to $240 \mathrm{mg}$ was from the cerebrum of a MAM-induced microencephalic rat. The subcortex was also homogenized at $0^{\circ} \mathrm{C}$ for $5 \mathrm{~min}$ in the chilled $0.1 \mathrm{M}$ phosphate buffer (pH 8.0) and was used as the enzyme solution.

Assay of $A C h E$ and $C h E$ activities, Activities of $\mathrm{AChE}$ and $\mathrm{ChE}$ were determined by the spectrophotometric method of Ellman et al. ${ }^{18)}$ AcTCh iodide and BuTCh iodide were used as the substrates for $\mathrm{AChE}$ and $\mathrm{ChE}$ respectively. The reaction mixture contained $0.48 \mathrm{~mm}$ AcTCh or $0.96 \mathrm{~mm}$ BuTCh, $86.5 \mathrm{~mm}$ phosphate buffer ( $\mathrm{pH} 8.0$ ), $0.32 \mathrm{~mm}$ 5,5-dithiobis-2nitrobenzoate, $0.57 \mathrm{~mm}$ sodium bicarbonate and approximate amounts of the enzyme in a cuvette which was kept at $37^{\circ} \mathrm{C}$. The absorbance at $412 \mathrm{~nm}$ was measured every 30 seconds for 6 or $8 \mathrm{~min}$ and the increase in the absorbance per min was determined. Activities of both enzymes were expressed as $\mu$ mole of the substrates hydrolyzed $/ \mathrm{min} \cdot \mathrm{g}$ wet weight of tissue.

\section{RESULTS}

\section{Changes in the body weight and cerebral weight during development}

At the ages of 10 and 20 days, the body weight of the microencephalic rat was lower than that of the normal animal $(P<0.001$ and $P<0.01$ respectively), but no significant difference was observed at other ages (Table I). The change with age in the cerebral weight of the microencephalic rat was also compared with that in the cerebral weight of the normal one, because the MAM-induced anatomical changes occurred in this organ. The cerebra of both the control and microencephalic rats grew rapidly from day 10 and to day 30 , and thereafter the growth slowed down up to the age of day 90 . The cerebral weight of the microencephalic rat was approximately 55 $70 \%$ less than that of control one.

\section{Comparison of AChE activity}

The activity of AChE most rapidly increased between day 10 and 30 of postnatal period, and a little increase was also observed thereafter in the cerebra of the control and MAMinduced microencephalic rats. The activity of the enzyme per the cerebrum of the microencephalic rat was about $25 \sim 60 \%$ less than

Table I. Changes in the Body and Cerebral Weights during Development Each value represents the mean $\pm S D$ and the number of determinations is shown in parentheses.

\begin{tabular}{|c|c|c|c|c|}
\hline \multirow{2}{*}{$\begin{array}{l}\text { Age } \\
\text { (day) }\end{array}$} & \multicolumn{2}{|c|}{ Body weight (g) } & \multicolumn{2}{|c|}{ Cerebral weight (g) } \\
\hline & Control & Microencephalic & Control & Microencephalic \\
\hline 10 & $15.0 \pm 1.8(8)$ & $11.8 \pm 1.5(14)^{a}$ & $0.61 \pm 0.04(8)$ & $0.19 \pm 0.03(6)^{a}$ \\
\hline 20 & $28.4 \pm 2.9(6)$ & $21.1 \pm 5.0(16)^{b}$ & $0.88 \pm 0.02(6)$ & $0.28 \pm 0.05(7)^{a}$ \\
\hline 30 & $58.6 \pm 10.8(7)$ & $58.1 \pm 9.3(10)$ & $0.97 \pm 0.06(7)$ & $0.39 \pm 0.07(9)^{a}$ \\
\hline 60 & $192.3 \pm 20.4(7)$ & $173.6 \pm 22.6(9)$ & $1.08 \pm 0.07(7)$ & $0.47 \pm 0.09(9)^{a}$ \\
\hline 90 & $251.4 \pm 6.9(8)$ & $255.0 \pm 15.0(6)$ & $1.15 \pm 0.06(8)$ & $0.53 \pm 0.07(6)^{a}$ \\
\hline
\end{tabular}

Symbols denote: a significant at $P<0.001, \quad b$ significant at $P<0.01$. 

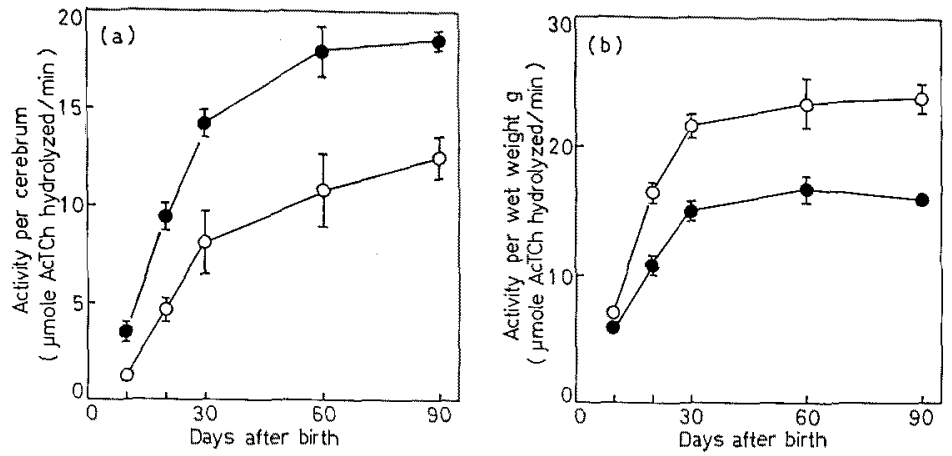

FIG. 1. Changes in the Activity of AChE in the Cerebra of MAM-induced Microencephalic and Control Rats.

Each point represents the mean \pm SD for 6 or 7 determinations. Symbols denote: 0 , microencephalic rats, and control rats. (a) Activity of AChE per the cerebrum; differences between control and microencephalic groups were significant at $P<0.001$. (b) Activity of AChE per $g$ wet weight of the cerebrum; differences between the two groups were significant at $P<0.001$.
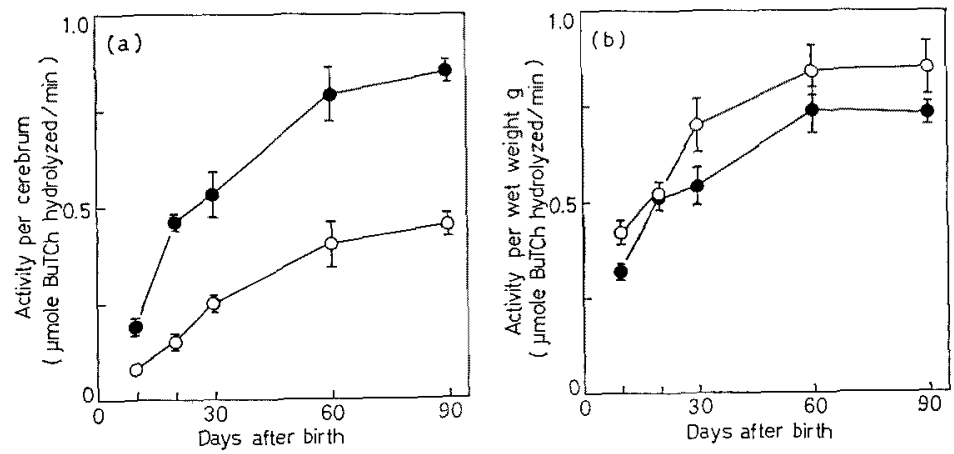

FIG. 2. Changes in the Activity of ChE in the Cerebra of MAM-induced Microencephalic and Control Rats.

Each point represents the mean $\pm S D$ for 6 or 7 determinations. Symbols denote: $O$ microencephalic rats, and control rats. (a) Activity of ChE per the cerebrum; differences between control and microencephalic groups were significant at $P<0.001$. (b) Activity of ChE per $\mathrm{g}$ wet weight of the cerebrum; differences between the two groups were significant on day 10 and 30 at $P<0.001$, and on day 60 and 90 at $P<0.01$.

that of the control one at all ages studied (Fig. 1 (a)), and the differences were significant at $P<0.001$. The decrease in the AChE activity per the cerebrum of microencephalic rats might partly be due to the decrease in cerebral weight, but the deficit in $\mathrm{AChE}$ activity was much less than that expected on a calculation from the decrease in the cerebral weight. Therefore, the enzyme activity expressed as units per $g$ wet weight of the cerebrum of the microencephalic rat was higher than that of the normal animal at all ages $(P<0.001)$. The
AChE activity per $\mathrm{g}$ wet weight increased rapidly until day 30 and thereafter became nearly constant (Fig. 1 (b)).

\section{Comparison of ChE activity}

The activity of ChE per the cerebrum was lower in the microencephalic rat than in the control animal $(P<0.001)$, reflecting the decrease in the cerebral weight (Fig. 2 (a)). However, in the microencephalic rats, the deficit in ChE activity was less than that expected from the decrease in the cerebral weight. ChE 
activity per $g$ wet weight of the cerebrum of the microencephalic rat was also higher than that of the organ of the control animal on day 10 and 30 at $P<0.001$ and on day 60 and 90 at $P<0.01$ although no difference was found on day 20 (Fig. 2 (b)).

The relationship between the activity of $A C h E$ and the cerebral weight

Various size of the cerebra were taken out from the 20-day-old rats of which mothers were injected with different doses of MAM-acetate on day 15 of pregnancy. The AChE activity per the cerebrum decreased with the decrease in the cerebral weight. However, the enzyme activity per $g$ wet weight of the cerebrum increased against the decrease in the cerebral weight (Fig. 3). There was a good correlation between the cerebral activity of the enzyme and the weight of the cerebrum, and the correlation coefficient was -0.953 .

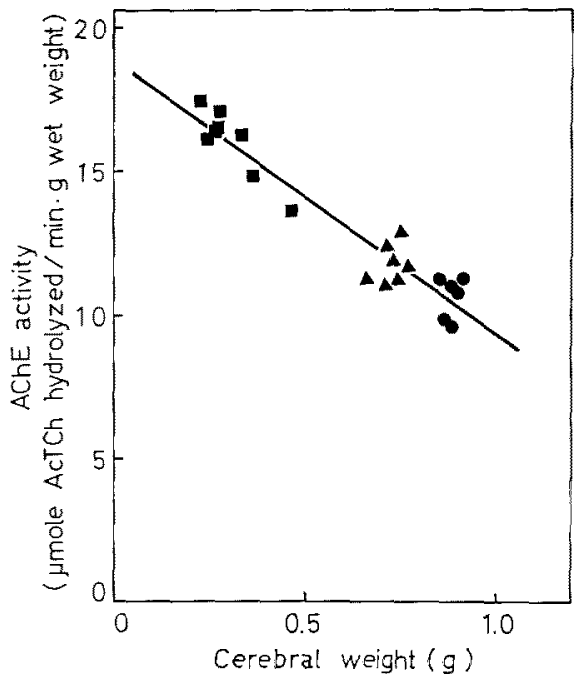

Fig. 3. The Relationship between the Activity of AChE and the Cerebral Weight.

The cerebra were taken out from the 20 days old rats of which mothers were injected with 0 ( ), 10 (A), and $20(\mathbf{D}) \mathrm{mg}$ of MAM-acetate $/ \mathrm{kg}$ body weight on the 15 th day of pregnancy.

\section{The activity of $A C h E$ in the subcortex}

There were significant differences $(P<0.001)$ between the microencephalic and control 60 -
Table II. Cerebral. and Subcortical Weights AND THE ACTIVITIES OF ACETYLCHOLINESTERASE in Control and MAM-INDUCED MicroenCEPHALIC RATS

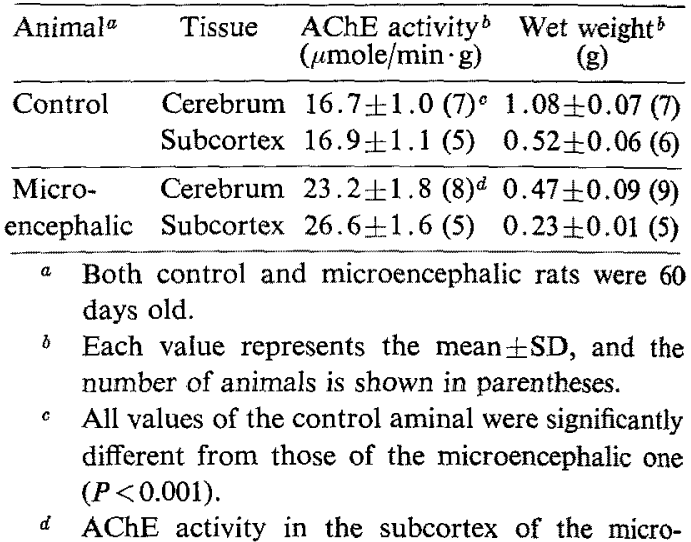
encephalic rats was significantly higher than that in the whole cerebrum of them $(P<0.001)$.

day-old rats in the weight and AChE activity of the cerebrum and the cerebral subcortex (Table II). The AChE activity in the subcortex of microencephalic rats was higher than that in the whole cerebrum of them $(P<0.001)$, although there was no difference between the AChE activities in the whole cerebrum and in the subcortex of the control animals.

\section{DISCUSSION}

On day 10 and 20, the MAM-induced microencephalic rats were lighter than the control rats in their body weight, but thereafter no significant difference was observed. The toxic effect of MAM may be persistent during the neonatal period. The cerebral weight of the microencephalic rats was less than that of the control animal (Table I). Microencephaly is well known to be also induced by X-ray irradiation, ${ }^{17}$ ) high temperature, ${ }^{18}$ prenatal undernutrition, ${ }^{197}$ and methylnitrosourea. ${ }^{201}$ In these microencephalic rats, the biochemical development of the ontogenetically newer areas was more greatly affected than that of the older areas of the central nervous system. ${ }^{21}$ ) Therefore, the activities of $\mathrm{AChE}$ and $\mathrm{ChE}$ in the cerebral cortex of the MAM-induced microencephalic rat should decrease if there 
were no plasticity in cholinergic neurons of the cerebrum.

Increase of ChE activity per $\mathrm{g}$ wet weight of the cerebrum (Fig. 2 (b)) suggested that metabolism of glial cells was selectively altered by the prenatal MAM-treatment because $\mathrm{ChE}$ in the nervous tissues is localized in glial cells. $^{15)}$ The alteration observed in this study persisted for as long as 90 days after birth with the only exception of day 20. Transient treatment of the pregnant rat with MAM may produce some prolonged alteration in the metabolism of glial cells of the offspring.

AChE is important in synaptic and cholinergic transmission: it is in the nervous cells, axons, and endings of all choline-containing neurons, ${ }^{15}$ and hydrolyzes $\mathrm{ACh}$ liberated into synaptic vesicular crevice. The total activity of AChE in the whole cerebrum of the microencephalic rat was lower than that of the control animal (Fig. 1 (a)), but this enzyme activity per $g$ wet weight was remarkably higher in the cerebrum of the microencephalic animal than in that of the normal one (Fig. 1 (b)). Total activity of AChE in the cerebrum was proportional to the cerebral weight, but the activity per $g$ wet weight of the cerebrum was linearly increased in proportion to the decrease in the cerebral weight (Fig. 3). These findings suggest some compensatory mechanism or plasticity ${ }^{22}$ ) in the cerebrum of the microencephalic rat, and the suggestion is consistent with the fact that, although the microencephalic rats were significantly inferior in the maze performance to the control animals, ${ }^{11,12}$ ) the extent of inferiority was not so large as the degree of the reduction in their cerebral weight. AChE activity in the subcortex of the microencephalic rats was $15 \%$ higher than that in the other tissue (Table II). Therefore, relatively high plasticity of the cerebrum may exist in the ontogenetically old areas.

Adlard and Dobbing found that AChE activity in the cerebellum of adult rats receiving one dose of X-ray to the head on day 6 was significantly elevated, and they suggested that the increased AChE activity was explained by plasticity of cholinergic neurons. ${ }^{23)}$ It must be noticed that the cerebellum of 6-day-old suckling rats corresponds ontogenetically to the cerebrum of 15-day-old fetal rats after pregnancy. ${ }^{20)}$

Substantially the MAM-induced microencephalic rat livers for over a year without gross deficiencies in physiology or behavior. ${ }^{8}$ ? The observation in the present study suggests that acetylcholine would be increasingly liberated from the cholinergic neurons of the reduced cerebrum for the microencephalic rat to adapt itself to circumstances, and that the increased rate of synthesis of $\mathrm{AChE}$ would be followed. This suggestion may be supported by the fact that significant increase in the activity of $\mathrm{AChE}$ has been found in brain regions of the rat having experience. ${ }^{22)}$ Stavinoha et al $^{24)}$ found a slight correlation between the concentration of acetylcholine and the activity of $\mathrm{AChE}$ in regional areas of the rat brain.

Recently, Matsutani et al ${ }^{25)}$ reported that no difference in the activity of choline acetyltransferase was found between brain regions of the MAM-induced microencephalic rat and those of the normal animal. The difference of these effects induced by the prenatal MAMtreatment on both cerebral AChE and choline acetyltransferase may provide evidence for the specific property of the cerebrum and the selective action of MAM to the constitutive enzymes of the cholinergic systems.

$\mathrm{AChE}$ in the brain of rats existing in multiple forms, ${ }^{23}$ determination of its activity using AcTCh as a substrate may not give a true picture of the MAM-induced changes in the activities of these isozymes. Therefore, it is necessary to determine in which regions of the cerebrum and in what proportion each $\mathrm{AChE}$ isoenzyme is distributed in the rat cerebrum and how strongly each enzyme is affected by the prenatal MAM-treatment.

\section{REFERENCES}

1) L. T. Kurland and D. W. Muider, Neurology, 4, 355 (1954); idem, ibid., 4, 438 (1954).

2) M. G. Whiting, Fed. Proc., 23, 1343 (1964).

3) A. Kobayashi, ibid., 31, 1476 (1972). 
4) K. Nishida, A. Kobayashi and T. Nagahama, Bull. Agric. Chem. Soc. Jpn., 19, 77 (1955).

5) M. G. Whiting, Econ. Botany, 17, 271 (1963).

6) G. L. Laqueur, O. Mickelsen, M. G. Whiting and L. T. Kurland, J. Natl. Cancer Inst., 31, 919 (1963).

7) A. Kobayashi and H. Matsumoto, Arch. Biochem. Biophys., 110, 373 (1965).

8) M. Spatz and G. L. Laqueur, Proc. Soc. Exp. Biol. Med., 129, 705 (1968).

9) Y. Nagata and H. Matsumoto, ibid., 132, 383 (1969).

10) H. Matsumoto, M. Spatz and G. L. Laqueur, $J$. Neurochern., 19, 297 (1972).

11) Y. Nagata, G. Ito, M. Hibino and K. Hayashi, Nippon Nôgeikagaku Kaishi, 46, N156 (1972).

12) T. Matsutani, Y.Tsukada and M. Nomura, $J$. Physiol. Soc. Jpn., 36, 295 (1974).

13) R. K. Haddad, A. Rabe, G. L. Laqueur, M. Spatz and M. P. Valsamis, Science, 163, 88 (1969).

14) M. R. Rosenzweig, D. Krech and E. L. Bennett, Psychol. Bull., 57, 476 (1960).

15) N. Seiler, "Handbook of Neurochemistry," Vol. I, ed. by A. Lajtha, Plenum Press, New YorkLondon, 1969, p. 325.

16) G. L. Ellman, K. D. Courtney, V. Andres and R. M. Featherstone, Biochem. Pharmacol., 7, 88 (1961).

17) S. P. Hicks, C. J. Damato and M. J. Lowe, J. Comp. Neurol., 113, 435 (1959).

18) M. J. Edwards, Arch. Path., 84, 42 (1967).

19) J.L. Smart, J. Dobbing, B.P.F. Adlard, A. Lynch and J. Sands, J. Nutr., 103, 1327 (1973).

20) H. Nishimura and T. Tanimura, Adv. Neurol. Sci., 16, 310 (1972).

21) G. J. Maletta, A. Vernadakis and P.S. Timiras, J. Neurochem., 14, 647 (1967).

22) E. L. Bennett, M. C. Diamond, D. Krech and M. R. Rosenzweig, Science, 146, 610 (1964).

23) B. P. F. Adlard and J. Dobbing, Exp. Neurol., 35, 547 (1972).

24) W.B. Stavinoha, S.T. Weintraub and A.T. Modak, J. Neurochem., 23, 885 (1974).

25) T. Matsutani, M. Tamura and Y.Tsukada, $J$. Physiol. Soc, Jpn., 37, 264 (1975). 